Я. СЕРЕДНИЦКИИ, В. СУПРУН, К. КИИС, О. ЦЕЛЮХ, Е. РОТЕР, В. БОДАК

\title{
ИССЛЕДОВАНИЕ ИЗОЛЯЦИОННЫХ И АНТИКОРРОЗИОННЫХ ХАРАКТЕРИСТИК БИТУМНЫХ ПОКРЫТИИ, СОДЕРЖАЩИХ ПРОДУКТЫ СЛАНЦЕПЕРЕРАБОТКИ
}

\author{
(Представил Н. Клесмент)
}

Продукты сланцепереработки нашли широкое применение при проведении кровельных и гидроизоляционных работ, а также в составе антикоррозионных материалов $\left[{ }^{1-3}\right]$. Известно также использование керогена (концентрата органического вещества прибалтийских сланцев) и отходов сланцепереработки (золы, молотого известняка) в качестве наполнителей строительных материалов [ $\left.{ }^{4}\right]$.

Своеобразный состав сланцевых смол, характеризующийся высоким содержанием фенолов и нейтральных кислородсодержащих соединений, позволяет расширить их применение в качестве пластификаторов и антисептических добавок, а также составных компонентов изоляционных и антикоррозионных покрытий.

В связи с вышеизложенным несомненную актуальность представляет изучение гидроизоляционных и антикоррозионных характеристик битумно-сланцевых покрытий (водопоглощения, относительной диэлектрической проницаемости $\varepsilon$, проводимости $G$ ). Одним из критериев подбора композиций для исследования являлись удовлетворительные физикомеханические и физико-химические показатели (растяжимость, пенетрация, адгезия к стальной фольге, температура размягчения и пр.).

Объектом модификации выбран битум изоляционный нефтяной марки БНИ-IV (ГОСТ 6617-76), а в качестве модифицирующих компонентов следующие продукты сланцепереработки:

1. Кукерсоль (К) (ТУ 38 10938-75).

2. Пек кукерсоля (ПК) - полупродукт производства кукерсоля с температурой размягчения $63^{\circ} \mathrm{C}$ по методу кольца и шара.

3. Мастика битумно-латексно-кукерсолевая (БЛК) (ТУ 38 103-81). $80^{\circ} \mathrm{C}$.

4. Сланцевая смола (СС) с условной вязкостью по Энглеру $6,5^{\circ}$ при

5. Сланцевое дорожное масло (ДМ) (ТУ 38 10913-76) с условной вязкостью по Энглеру $3,5^{\circ}$ при $75^{\circ} \mathrm{C}$.

6. Молотый карпатский сланец (MKC) месторождения Верхнее Синевидное Львовской области. Минеральная часть этого сланца состоит из гидрослюды, монтмориллонита и их неупорядоченных сростков, органическая часть $(10-15 \%$ мас.) содержит гуминовые соединения, что обеспечивает хорошую диспергируемость в органических средах [5].

Для сравнения в состав битумных покрытий вводили обладающие определенным ингибирующим действием [6] кубовые остатки ректификации синтетических жирных кислот (КО СЖК) (ОСТ 38 01189-80) и присадку АКОР-1 (ГОСТ 15171-70). Указанные продукты нашли применение в антикоррозионной и строительной практике. 
Синтез мастичных покрытий осуществляли в лабораторных металлических реакторах по стандартной методике [7]. Модифицирующие вещества вводили в расплав битума при $130-160^{\circ} \mathrm{C}$.

Температуру размягчения композиций определяли согласно ГОСТу 11506-73; растяжимость - по ГОСТу 11505-75; пенетрацию - по ГОСТу 11504-78; адгезию к стальной фольге - по ГОСТу 16140-78. Относительное водопоглощение определяли по изменению массы образцов в процессе выдержки в дистиллированной воде при $25^{\circ} \mathrm{C}$. Диэлектрические характеристики исследовали по ГОСТу 22372-77. Измерения проводили в области частот $0,3-20,0$ кГц.

Результаты определения основных характеристик исследованных материалов (табл. 1) показали, что модификация нефтяного битума БНИ-IV сланцевыми продуктами способствует повышению растяжимости с 1,2 до 4,3 см, адгезии к стальной фольге - с 1,1 до 1,4 H/м. Максимальным показателем растяжимости (4,3 см) обладает система БНИIV-ДM, максимальным показателем адгезии $(3,6 \mathrm{H} / \mathrm{M})-$ состав, содержащий $3 \%$ мас. КО СЖК. В композиций БНИ-IV-ПК адгезия снижается до $1,0 \mathrm{H} / \mathrm{M}$. Введение в состав битумных композиций сланцевых продуктов и ингибиторов в основном снижает пенетрацию и температуру размягчения. Следовательно, их количество не должно превышать $10 \%$ мас.

Таблица 1

Характеристика композиций на основе нефтяного битума, модифицированного сланцевыми продуктами

\begin{tabular}{|c|c|c|c|c|c|c|}
\hline Композиция & 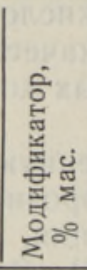 & 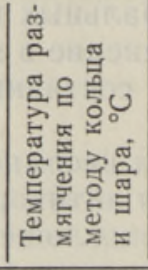 & 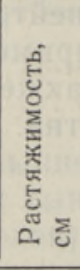 & 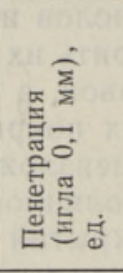 & 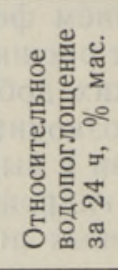 & 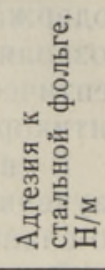 \\
\hline Битум БНИ-IV без модификатора & & 90 & 1,2 & 36 & 0,20 & 1,1 \\
\hline БНИ-IV-K & 10 & 88 & 1,3 & 13 & $-0,05$ & 1,3 \\
\hline БНИ-IV-ПК & 10 & 83 & 1,6 & 13 & 0,10 & 1,0 \\
\hline БНИ-IV-мастика БЛК & 10 & 70 & 2,3 & 13 & $-0,22$ & - \\
\hline БНИ-IV-CC & 10 & 77 & 2,5 & 14 & 0,29 & 1,4 \\
\hline БНИ-IV-ДМ & 10 & 68 & 4,3 & 40 & $-0,24$ & 1,3 \\
\hline БНИ-IV-МКС & 10 & 91 & 2,0 & 16 & 0,09 & 1,1 \\
\hline БНИ-IV-КО СЖК & 3 & 77 & 2,8 & 30 & 0,29 & 3,6 \\
\hline БНИ-IV-АКОР-1 & 3 & 76 & 1,8 & 2,8 & 0,23 & 1,2 \\
\hline
\end{tabular}

Изменение одного из основных изоляционных показателей - водопоглощения на основе суточных данных - противоречиво и требует более детального исследования. Судя по кинетическим кривым, характеризующим закономерности изменения массы образцов в течение длительного времени (рис. 1), введение в состав битумных покрытий МКС, ПК, СС в диапазоне $0-480$ ч мало влияет на изменение водопоглощения. Более существенным изменениям подвержены образцы, модифицированные $\mathrm{K}$ и мастикой БЛК - кривые 5 и 6 смещены в зону отрицательных значений. По абсолютной величине колебания изменения массы невелики и составляют от $+0,6$ до $-0,8 \%$ мас. Эти закономерности в основном сохраняются при более длительной выдержке образцов в воде. Так, водопоглощение БНИ-IV и систем БНИ-IV-CC, БНИ-IV-MKС за 1000 ч составляет $0,52,0,44,0,38 \%$ мас. соответ- 
ственно. Снижение массы образцов БНИ-IV, модифицированных мастикой БЛК, КО СЖК, ДМ и К, за указанный промежуток времени составляет $1,72,0,38,0,68$ (586 ч до разрушения) и $2,38 \%$ мас. соответственно.

Процессы, протекающие при длительном воздействии воды на битуминозные материалы - увеличение массы за счет водопоглощения либо уменьшение ее за счет миграции гидрофильных составляющих, в значительной мере определяют характер диэлектрических (изоляционных) и антикоррозионных (защитных) свойств покрытий. Процессы сорбции и диффузии влаги через изоляционные материалы и изменения диэлектрических и антикоррозионных параметров взаимосвязаны и их

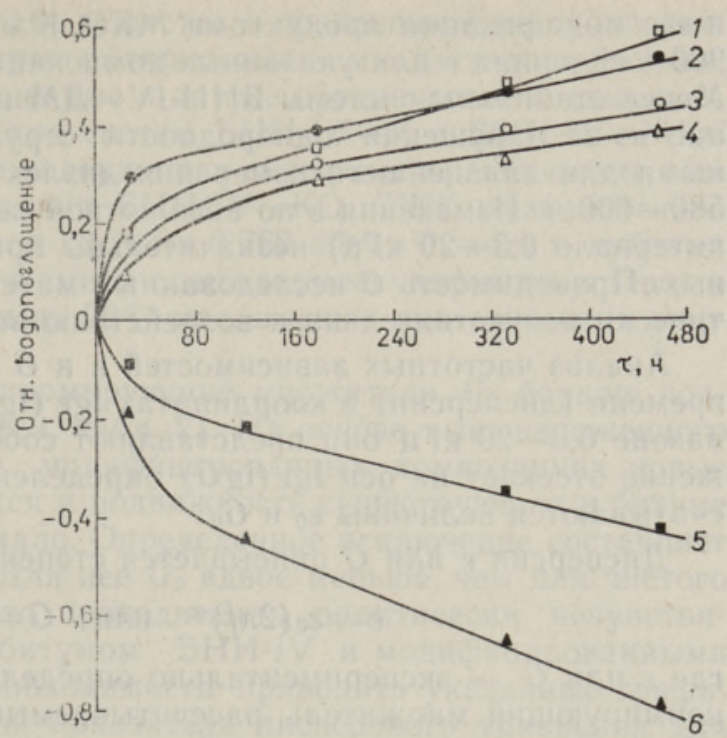

Рис. 1. Влияние сланцевых модификаторов на водопоглощение битумных композиций: 1 - БНИ-IV, 2 - БНИ-IV-CС, 3 - БНИ-IV-ПК, 4 - БНИ-IV-MКС, 5 - БНИ-IV-мастика БЛК, 6 БНИ-IV-K. необходимо рассматривать комплексно.

Исследованию диэлектрических характеристик подвергали битумносланцевые покрытия и системы БНИ-IV-КО СЖК, МБР-90-КО СЖК. Композицию на основе битумно-резиновой мастики МБР-90 (ГОСТ 15836-79) и КО СЖК (3\% мас.), характеризующуюся растяжимостью $3,6 \mathrm{~cm}$, пенетрацией 30 ед, температурой размягчения $83^{\circ} \mathrm{C}$, относительным суточным водопоглощением $0,11 \%$ мас., синтезировали и исследовали по вышеописанным методикам.

По кинетическим кривым (рис. 2), характеризующим изменение относительной диэлектрической проницаемости покрытий на частоте 1 кГц в процессе выдержки в дистиллированной воде (кривая 4 является общей для битума БНИ-IV и системы БНИ-IV-K), видно, что наиболее стабильными показателями при водопоглощении обладает БНИ-IV

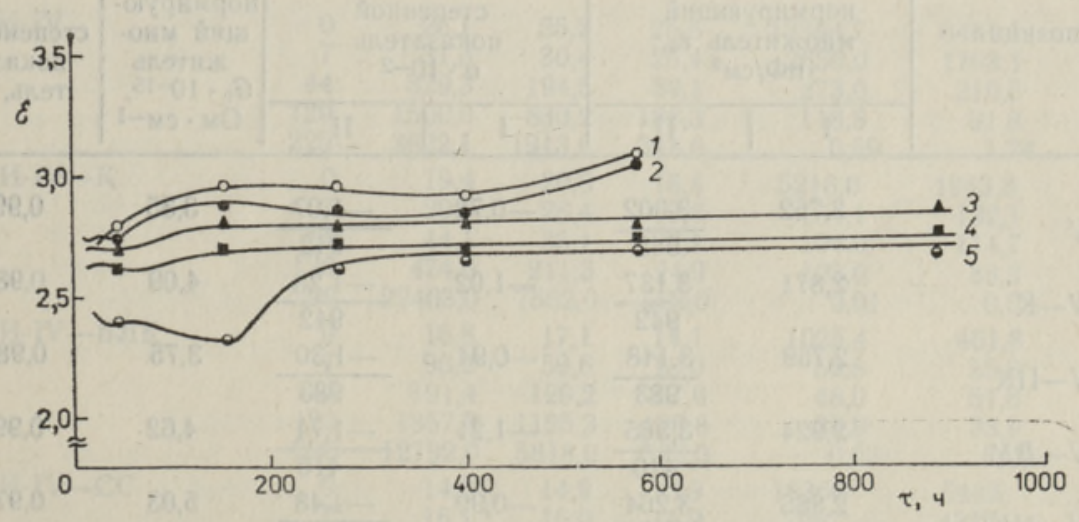

Рис. 2. Кинетика изменения относительной диэлектрической проницаемости битумных композиций при водопоглощенин: 1 - МБР-90-КО СЖК, 2 - БНИ-IV-ДМ, $3-$ БНИ-IV-MКС, 4 - БНИ-IV н БНИ-IV-K, 5 - БНИ-IV-KO СЖК. 
и его модификации продуктами МКС, К и КО СЖК. В интервале 250-900 ч величина $\varepsilon$ для указанных композиций практически не изменяется. Менее стабильны системы БНИ-IV-ДМ и МБР-90-КО СЖК. Последние из-за нарушения однородности структуры становятся непригодными для дальнейшего измерения диэлектрических показателей через $580-600$ ч. Изменения $\varepsilon$ по абсолютной величине на других частотах (в интервале $0,3-20$ кГц) незначительны при аналогичном характере кривых. Проводимость $G$ исследованных материалов на всех частотах практически нечувствительна к воздействию водной среды.

Анализ частотных зависимостей $\varepsilon$ и $G$ для одинаковых промежутков времени (дисперсии) в координатах $\lg \varepsilon(\lg G)$ и $\lg f$ показывает, что в диапазоне $0,3-20$ кГц они представляют собой прямые линии. Их продолжение отсекает на оси $\lg \varepsilon(\lg G)$ определенные отрезки, из которых рассчитываются величины $\varepsilon_{0}$ и $G_{0}$.

Дисперсия $\varepsilon$ или $G$ описывается степенным уравнением

$$
\varepsilon=\varepsilon_{0}(2 \pi f)^{\alpha} \text { или } G=G_{0}(2 \pi f)^{a},
$$

где $\varepsilon$ или $G$ - экспериментально определенный параметр; $\varepsilon_{0}$ или $G_{0}-$ нормирующий множитель, рассчитываемый из величин $\lg \varepsilon$ или $\lg G$, отсекаемых на оси ординат продолжением прямых частотных зависимостей; $f-$ линейная частота, кГц; $\alpha$ и $a-$ константы для данного материала, равные тангенсу угла наклона логарифмических зависимостей $\varepsilon$ и $G$ от логарифма частоты.

Величины нормирующих множителей и степенных показателей уравнения дисперсии диэлектрических характеристик модифицированных битумных композиций в исходном состоянии и после длительной выдержки в дистиллированной воде близки по абсолютным значениям (табл. 2), что свидетельствует о хорошей совместимости модификаторов с битумом БНИ-IV. Максимальным значением $\varepsilon_{0}\left(2,924\right.$ п $\left.Ф / \mathrm{cm}^{2}\right)$ в исходном состоянии обладает композиция БНИ-IV-ДМ. Это можно объяс-

таблица 2

Показатели дисперсии диэлектрических характеристик модифицированных битумных покрытий в исходном состоянии (I) и после выдержки в дистиллированной воде (II) (часы выдержки - в знаменателе)

\begin{tabular}{|c|c|c|c|c|c|c|}
\hline \multirow{3}{*}{ Композиция } & \multicolumn{4}{|c|}{$\begin{array}{c}\text { Относительная диэлектрическая } \\
\text { проницаемость }\end{array}$} & \multicolumn{2}{|c|}{ Проводимость } \\
\hline & \multicolumn{2}{|c|}{$\begin{array}{c}\text { нормирующий } \\
\text { множитель } \varepsilon_{0} \text {, } \\
\pi \Phi / \mathrm{cm}^{2}\end{array}$} & \multicolumn{2}{|c|}{$\begin{array}{l}\text { степенной } \\
\text { показатель } \\
\alpha \cdot 10^{-2}\end{array}$} & \multirow{2}{*}{$\begin{array}{c}\text { нормирую- } \\
\text { щий мно- } \\
\text { житель } \\
G_{0} \cdot 10^{-15} \\
\text { Ом } \text { см }^{-1}\end{array}$} & \multirow[t]{2}{*}{$\begin{array}{c}\text { степенной } \\
\text { показа- } \\
\text { тель, } a\end{array}$} \\
\hline & I & II & I & II & & \\
\hline БНИ-IV & 2,762 & $\frac{3,002}{942}$ & $-0,72$ & $\begin{array}{r}-1,07 \\
942\end{array}$ & 3,35 & 0,991 \\
\hline БНИ-IV-К & 2,871 & $\frac{3,137}{942}$ & $-1,02$ & $\begin{array}{r}-1,28 \\
942\end{array}$ & 4,09 & 0,985 \\
\hline БНИ-IV-ПК & 2,769 & $\frac{3,148}{983}$ & $-0,94$ & $\begin{array}{r}-1,30 \\
983\end{array}$ & 3,75 & 0,989 \\
\hline БНИ-IV-ДМ & 2,924 & $\frac{3,365}{410}$ & $-1,21$ & $\begin{array}{r}-1,71 \\
410\end{array}$ & 4,62 & 0,999 \\
\hline БНИ-IV—MКС & 2,886 & $\frac{3,264}{830}$ & $-0,99$ & $\frac{-1,48}{830}$ & 5,03 & 0,974 \\
\hline БНИ-IV-КО СЖК & 2,793 & $\begin{array}{c}3,119 \\
888\end{array}$ & $-0,88$ & $\begin{array}{r}-1,41 \\
888\end{array}$ & 1,56 & 1,066 \\
\hline
\end{tabular}


нить тем, что в состав ДМ входят вещества с повышенной по сравнению с компонентами нефтяного битума полярностью - многоатомные фенолы, кислородсодержащие, ненасыщенные и другие органические соединения. Несколько ниже значения $\varepsilon_{0}$ для систем БНИ-IV-K и БНИ-IV-MKC

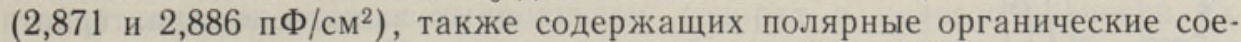
динения. Изменение $\varepsilon_{0}$ композиции БНИ-IV-KO СЖК незначительно по сравнению с чистым битумом $\left(2,793\right.$ и 2,762 пФ/см $\left.{ }^{2}\right)$, хотя в кубовых остатках ректификации СЖК в смеси с высокомолекулярными углеводородами и смолами содержится до $20 \%$ мас. высших синтетических жирных кислот.

По абсолютной величине нормирующие множители $G_{0}$ больше подвержены изменениям, чем $\varepsilon_{0}$ (см. табл. 2). На основе вышеизложенного можно предположить, что в модифицированных композициях новые носители зарядов не образуются и подвижность существующих в битуме БНИ-IV зарядов изменяется мало. Определенное исключение составляет система БНИ-IV-KO СЖК. Для нее $G_{0}$ вдвое меньше, чем для чистого БНИ-IV. Следует отметить, что проводимость практически нечувствительна к поглощению влаги битумом БНИ-IV и модифицированными материалами, поэтому нет необходимости приводить указанные графические зависимости. Степенной показатель дисперсного уравнения для всех исследованных композиций в течение 1000 ч не изменяется. Нормирующий множитель $G_{0}$ обнаруживает некоторую тенденцию к увеличению при водопоглощении материалов, однако по абсолютной величине эти изменения очень малы.

По абсолютной величине $\varepsilon_{0}$ можно в определенной мере судить о водостойкости композиций (см. табл. 2). Так, для БНИ-IV $\varepsilon_{0}$ через 942 ч

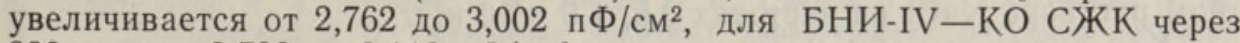

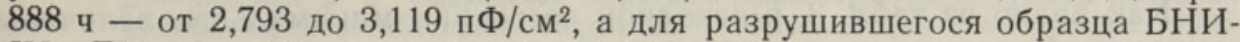
IV-ДМ через 410 ч - от 2,924 до 3,365 пФ/см².

Таблица 3

Величины емкости и сопротивления стального электрода, изолированного ингибированными битумными покрытиями (3\%-ный раствор $\mathrm{NaCl})$, на разных частотах

\begin{tabular}{|c|c|c|c|c|c|c|c|}
\hline \multirow{2}{*}{ Композиция } & \multirow{2}{*}{ 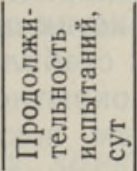 } & \multicolumn{3}{|c|}{ 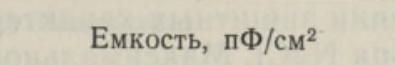 } & \multicolumn{3}{|c|}{ Сопротивление, Ом $\cdot$ см $\cdot 10^{6}$} \\
\hline & & 0,5 кГц & 1,0 кГц & 10 кГц & 0,5 кГц & 1,0 кГц & 10 кГц \\
\hline БНИ-IV & $\begin{array}{r}0 \\
7 \\
44 \\
120 \\
225\end{array}$ & $\begin{array}{r}25,1 \\
31,3 \\
329,3 \\
1500,0 \\
3622,1\end{array}$ & $\begin{array}{r}25,2 \\
30,4 \\
194,5 \\
830,2 \\
1913,0\end{array}$ & $\begin{array}{r}25,6 \\
25,4 \\
59,1 \\
186,3 \\
348,0\end{array}$ & $\begin{array}{r}13384,7 \\
2630,0 \\
273,0 \\
118,8 \\
0,69\end{array}$ & $\begin{array}{c}6411,1 \\
1703,1 \\
210,6 \\
91,8 \\
1,24\end{array}$ & $\begin{array}{r}1132,1 \\
454,2 \\
83,4 \\
36,6 \\
0,62\end{array}$ \\
\hline БНИ-IV-K & $\begin{array}{r}0 \\
7 \\
44 \\
120 \\
296\end{array}$ & $\begin{array}{r}19,4 \\
29,0 \\
44,1 \\
474,6 \\
22403,0\end{array}$ & $\begin{array}{r}20,6 \\
26,4 \\
33,1 \\
211,3 \\
7562,0\end{array}$ & $\begin{array}{r}18,4 \\
19,6 \\
22,1 \\
94,9 \\
583,0\end{array}$ & $\begin{array}{c}5216,0 \\
154,1 \\
104,0 \\
103,0 \\
0,01\end{array}$ & $\begin{array}{r}1943,3 \\
132,1 \\
114,7 \\
88,3 \\
0,02\end{array}$ & $\begin{array}{c}312,3 \\
67,1 \\
80,0 \\
53,4 \\
0,28\end{array}$ \\
\hline БНИ-IV-БЛК & $\begin{array}{r}0 \\
7 \\
44 \\
120 \\
296\end{array}$ & $\begin{array}{r}16,8 \\
90,2 \\
191,4 \\
1357,3 \\
12792,0\end{array}$ & $\begin{array}{r}17,1 \\
59,6 \\
129,2 \\
1125,3 \\
5618,0\end{array}$ & $\begin{array}{r}14,1 \\
18,0 \\
67,0 \\
496,8 \\
583,0\end{array}$ & $\begin{array}{c}1025,4 \\
59,8 \\
48,0 \\
35,9 \\
0,02\end{array}$ & $\begin{array}{c}461,8 \\
55,8 \\
61,6 \\
33,9 \\
0,02\end{array}$ & $\begin{array}{c}109,5 \\
41,0 \\
32,4 \\
23,3 \\
0,01\end{array}$ \\
\hline БНИ-IV-CC & $\begin{array}{r}0 \\
7 \\
44 \\
120 \\
296\end{array}$ & $\begin{array}{r}14,0 \\
16,1 \\
15,3 \\
20,3 \\
203,0\end{array}$ & $\begin{array}{r}14,9 \\
16,0 \\
16,3 \\
18,3 \\
193,0\end{array}$ & $\begin{array}{l}13,9 \\
14,9 \\
21,6 \\
16,2 \\
72,0\end{array}$ & $\begin{array}{r}18360 \\
7097 \\
1308 \\
5779 \\
794\end{array}$ & $\begin{array}{r}5445 \\
4377 \\
2297 \\
5754 \\
543\end{array}$ & $\begin{array}{l}884 \\
519 \\
461 \\
916 \\
430\end{array}$ \\
\hline
\end{tabular}




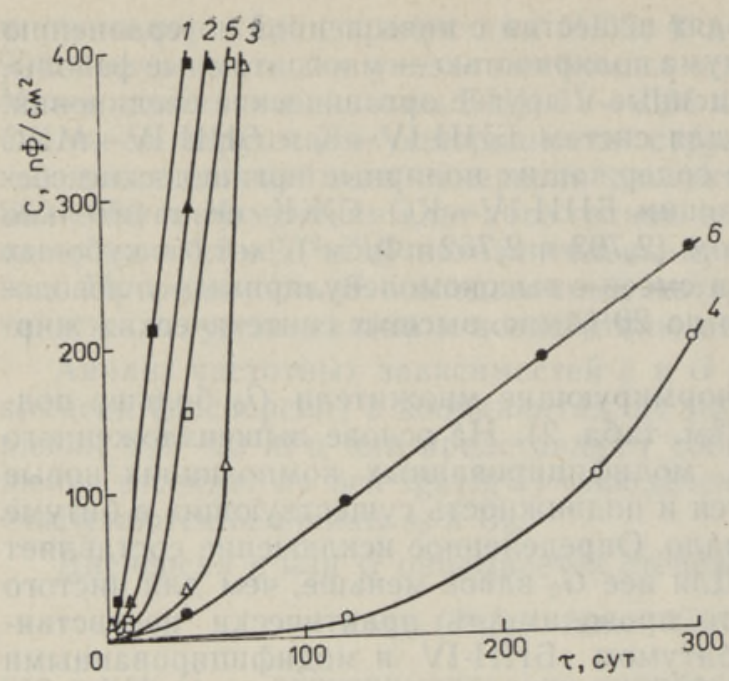

Рис. 3. Кинетика изменения емкости стального электрода с покрытием толщиной $0,1-0,2$ мм на основе компознций БНИ-IV; моднфнкаторы в $3 \%$-ном растворе $\mathrm{NaCl}$ на частоте 500 Гц: 1 БНИ-IV, 2 - БНИ-IV-БЛК, 3 - БНИ-IV-К, 4 - БНИ-IV-СС, 5 - БНИ-IV-AКОР-1, 6 БНИ-IV-KO СЖК.

ном растворе $\mathrm{NaCl}$ на частотах $0,5,1,0$ и 10 кГц.

Как видно из табл. 3, в исходном состоянии минимальные величины емкости обеспечивают покрытия на основе композиции, содержащей СС. Уменьшение величин емкости и, следовательно, рост защитных характеристик происходит в ряду: БНИ-IV $>$ БНИ-IV-K>БНИ-IV-БЛК> БНИ-IV-CС.

В процессе длительной (296 суток) выдержки в 3\%-ном растворе $\mathrm{NaCl}$ для всех битумных и битумно-сланцевых покрытий на исследованных нами частотах наблюдается тенденция к увеличению абсолютных величин емкости и уменьшению сопротивления стального электрода. Это свидетельствует о снижении защитных характеристик покрытий по мере проникания в них раствора $\mathrm{NaCl}$. Максимальной стабильностью емкости и сопротивления обладает стальной электрод с покрытием БНИ-IV-CC. Системы БНИ-IV-K и БНИ-IV-БЛК по данным показателям незначительно уступают исходному битуму.

Исследование изменения емкости стального электрода с покрытиями толщиной $0,1-0,2$ мм в $3 \%$-ном растворе $\mathrm{NaCl}$ на частоте 0,5 кГц (рис. 3) показало, что до 120 ч испытаний защитные свойства исследованных покрытий достаточно высоки и примерно одинаковы. Но уже через 296 ч емкость стального электрода, защищенного битумом БНЙ-IV, достигает

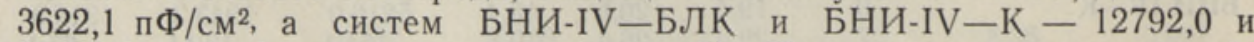
22403,0 пФ/см² соответственно (табл. 3). По антикоррозионным свойствам перечисленные системы значительно уступают системам БНИIV-CC и БНИ-IV-KО СЖК (рис. 3 , кривые 4 и 6 ; табл. 3 ).

\section{Выводы}

1. Сланцевые продукты (кукерсоль, пек кукерсоля, дорожное масло, сланцевая смола, а также мастика БЛК в количестве до 10\% мас.) образуют с нефтяным битумом БНИ-IV качественные покрытия. Модифицированные покрытия обладают по сравнению с исходным битумом повышенной растяжимостью и улучшенными антикоррозионными харак- 
теристиками. По гидроизоляционным параметрам (водостойкости, проводимости и относительной диэлектрической проницаемости) они незначительно уступают битумной основе.

2. Доступность, низкая себестоимость, технологичность и антисептические свойства сланцевых продуктов говорят о целесообразности их применения в качестве модификаторов битумных и полимернобитумных гидроизоляционных и антикоррозионных покрытий. Особенно перспективным модификатором является сланцевая смола с условной вязкостью по Энглеру $6,5^{\circ}$ при $80^{\circ} \mathrm{C}$.

\section{ЛИТЕ РА Т У РА}

1. Кийс К. Э., Короткевич Н. Г. Мастики и кровельные материалы на базе кукерсоля. Строит. материалы, 1983, № 6, 14-16.

2. Московкина Н. П. Новый кровельный и гидронзоляционный матернал -- руберан. Строит. матерналы, 1983, № 1, 20-21.

3. Горб С. И., Катишонок Л. А., Дзените Э. Я. Применение новых противокоррозионных лакокрасочных материалов на основе продуктов переработки прибалтийских сланцев. Рига, 1983.

4. Романова А. А., Комлев В. К., Ватажина В. И., Фрейман Г. Б., Корнышев Д. И., Прохоров А. Д. Использование отходов сланцеперерабатывающей промышленности в производстве полимерных строительных материалов. - Стронт. материалы, 1981, № 5, 18-19.

5. Минько С. С., Лузинов Н. А., Токарев В. С. Битуминозные аргиллиты менилитовой свиты как наполнители для полимерных композиционных материалов. - В кн.: Экономия материальных ресурсов и улучшение качества изделий и конструкций на основе применения новых полимерных материалов. Тез. респ. научн.техн. конф., вып. 1. Виноградово, 1985, 25.

6. Середницкий Я. А., Миндюк А. К., Целюх О. И., Супрун В. В., Дзиковский О. М., Домбровский $Б$. О. Повышение защнтных характеристик битумных покрытий модификацией ингибиторами коррозии. - Физ.-хим. мех. материалов, 1986, № 6, 88-91.

7. Козловская А. А. Полимерные и полимернобитумные материалы для защиты трубопроводов от коррозии. М., 1971.

8. Розенфельд Н. Л., Бурьяненко В. Н., Жигалова К. А. О мегодике исследования защитных свойств лакокрасочных покрытий емкостно-омическим методом. Лакокрасочные материалы и их применение, 1966, № 3, 62-65.

Физико-механический институт Академии наук Украинской ССР (Львов)

Сланцехимический завод «Кивиыли»
Поступила в редакщию 28/IX 1987

\section{J. SEREDNITSKI, V. SUPRUN, K. KIIS, O. TSELJUHH, E. ROTER, V. BODAK}

\section{POLLVKIVI OMBERTOOOTAMISE PRODUKTE SISALDAVATE BITUUMENKATETE ISOLATSIOONI- JA KORROSIOONIKINDLUSE NÄITAJATE UURIMINE}

On uuritud kukersiitse põlevkivi termilise lagundamise produktidega (kukersool, kukersooli pigi, erinevad ōlifraktsioonid ja bituumen-lateks-kukersoolmastiks), aga ka Karpaatide pőlevkiviga modifitseeritud bituumenkattemastiksite hüdroisolatsiooni ja veekindluse näitajaid ning tõestatud naftabituumenite sellise modifitseerimise otstarbekust.

Ya. SEREDNITSKY, V. SUPRUN, K. KIIS, O. TSELYUKH, Ye. ROTER, V. BODAK

\section{INVESTIGATION OF INSULATION AND CORROSION PROPERTIES OF BITUMEN COATINGS MODIFIED BY OIL-SHALE PROCESSING PRODUCTS}

Hydroisolation and water-resistant properties of bitumen coating mastics modified by Estonian oil-shale thermal decomposition products (kukersole and its pitches, different oil fractions and bitumen latex kukersole mastic) as well as by Carpathian oil-shale have been investigated. The expediency of such modifications of oil bitumens has been proved. 